\title{
Oxidative stress induces cell death partially by decreasing both mRNA and protein levels of nicotinamide phosphoribosyltransferase in PC12 cells
}

\author{
Cuiyan Zhou, Weihai Ying*
}

${ }^{1}$ Med-X Research Institute and School of Biomedical Engineering, Shanghai Jiao Tong University, Shanghai 200030, P.R. China

\#: Corresponding author

Weihai Ying, Ph.D.

Professor, School of Biomedical Engineering and Med-X Research Institute

Shanghai Jiao Tong University

1954 Huashan Road

Shanghai, 200030, P.R. China

E-mail: weihaiy@sjtu.edu.cn 


\begin{abstract}
Numerous studies have indicated critical roles of $\mathrm{NAD}^{+}$deficiency in both aging and multiple major diseases. It is critical to investigate the mechanisms underlying the $\mathrm{NAD}^{+}$deficiency under the pathological conditions. It has been reported that there was a decreased level of Nicotinamide phosphoribosyltransferase (Nampt) - an important enzyme in the salvage pathway of $\mathrm{NAD}^{+}$synthesis - under certain pathological conditions, while the mechanisms underlying the Nampt decrease require investigation. In this study we used differentiated PC12 cells as a cellular model to investigate the effects of oxidative stress on both the mRNA and protein levels of Nampt, as well as the role of this effect in oxidative stress-induced cell death: First, Nampt plays significant roles in both the $\mathrm{NAD}^{+}$synthesis and survival of the cells under basal conditions; second, $\mathrm{H}_{2} \mathrm{O}_{2}$ produced significant decreases in both the mRNA levels and the protein levels of Nampt; and third, $\mathrm{H}_{2} \mathrm{O}_{2}$ induced cell death partially by producing the decreases in the mRNA and protein levels of Nampt, since the Nampt inhibitor or the Nampt activator significantly exacerbated or attenuated the $\mathrm{H}_{2} \mathrm{O}_{2}$-induced cell death, respectively. Collectively, our study has indicated that oxidative stress can decrease both the mRNA and protein levels of Nampt, which has indicated a novel mechanism underlying the $\mathrm{NAD}^{+}$deficiency in aging and under multiple pathological conditions. Our study has also indicated that the decreased Nampt levels contribute to the $\mathrm{H}_{2} \mathrm{O}_{2}$ induced cell death, suggesting a new mechanism underlying oxidative cell death.
\end{abstract}

Keywords: Nampt; NAD ${ }^{+}$; Oxidative Stress; Cell Death; Aging. 


\section{Introduction}

Numerous studies have indicated that $\mathrm{NAD}^{+}$plays important roles in mutiple biological functions (1). Increasing evidence has also indicated $\mathrm{NAD}^{+}$deficiency as a critical pathological factor in multiple major diseases and pathological conditions $(1,2$, 3 ), including ischemic brain injury $(4,5)$, mayocardial ischemia (6), head trauma (7), epilepsy (8), and radiation-induced tissure injury (9) and chemotherapy agent-induced tissue injury (10). $\mathrm{NAD}^{+}$deficiency also appears to play an important role in the aging processess (11-13), which has been the biological basis for the widely used $\mathrm{NAD}^{+}$ supplements. It is of critical theoretical and medical significance to expose the mechanisms underlying the pathologocal alteration of $\mathrm{NAD}^{+}$metabolism. However, there has been significant shortage of information on this important topic.

There are two pathways for $\mathrm{NAD}^{+}$synthesis, including the de novo pathway and the salvage pathway (14). The nuclear enzyme Nicotinamide mononucleotide adenylyltransferase-1 (NMNAT-1) is a crucial enzyme in both the de novo pathway and the salvage pathway of $\mathrm{NAD}^{+}$synthesis (14). Mammals can use nicotinamide as the precursor for $\mathrm{NAD}^{+}$synthesis in the salvage pathway (15): Nicotinamide phosphoribosyltransferase (Nampt) converts nicotinamide to nicotinamide mononucleotide $(\mathrm{NMN})$ that can be converted to NAD ${ }^{+}$by NMNATs (15).

$\mathrm{NAD}^{+}$deficiency has been found in models of a number of diseases, which may result from poly (ADP-ribose) polymerase-1 (PARP-1) activation and decreased Nampt activity. It has been indicated that decreased Nampt activity is an important mechanism accounting for impaired $\mathrm{NAD}^{+}$synthesis capacity: Decreased Nampt 
activity has been found in the metabolic organs that are exposed to high-fat diet (HFD) (16), Drosophila pink1 mutants $(17)$, and aging $(16,18)$. It is critical to investigate the mechanisms underlying the decreased Nampt levels.

In this study we used PC12 cells as a cellular model to investigate the effects of oxidative stress on both the mRNA and protein level of Nampt. We also determined the roles of Nampt in the cell survival and $\mathrm{NAD}^{+}$metabolism in both basal and oxidative stress conditions. Our study has not only indicated significant roles of Nampt in the survival of PC12 cells under both basal and oxidative stress conditions, but also suggested novel mechanisms underlying the decreased Nampt in diseases and aging.

\section{Materials and methods}

\section{Materials}

$\mathrm{H}_{2} \mathrm{O}_{2}$ (323381) was purchased from Sigma Aldrich (St Louis, Missouri, USA). FK866 (HY-50876) and P7C3 (HY-15976) were purchased from MedChemExpress (New Jersey, USA). Nampt siRNAs and control siRNAs were purchased from GenePharma (Shanghai, China). Nampt primers were purchased from Sangon Biotech (Shanghai, China).

\section{Cell culture}

Differentiated PC12 cells were purchased from the Cell Resource Center of Shanghai Institute of Biological Sciences, Chinese Academy of Sciences (Shanghai, China). The cells were plated into $24-$ well cell culture plates at the initial density 
of $5 \times 10^{5}$ cells $/ \mathrm{ml}$ in Dulbecco's modified Eagle medium (Hyclone, Massachusetts, USA) containing $10 \%$ fetal bovine serum and $1 \%$ penicillin and streptomycin. The cells were cultured in a $5 \% \mathrm{CO}_{2}$ incubator at $37^{\circ} \mathrm{C}$.

\section{$\mathrm{NAD}^{+}$assay}

As previously described (19), $\mathrm{NAD}^{+}$concentrations were determined by the recycling assay. Briefly, samples were extracted in $0.5 \mathrm{~N}$ perchloric acid. After centrifugation at $12,000 \mathrm{~g}$ for $5 \mathrm{~min}$, the supernatant was obtained, which was neutralized to $\mathrm{pH} 7.2$ by using $3 \mathrm{~N}$ potassium hydroxide and $1 \mathrm{M}$ potassium phosphate buffer. After centrifugation at $12,000 \mathrm{~g}$ for $5 \mathrm{~min}$, the supernatants were mixed with a reaction media containing $1.7 \mathrm{mg} \mathrm{3-[4,5-dimethylthiazol-2-yl]-2,5-}$ diphenyl-tetrazolium bromide (MTT), $1.3 \mathrm{mg}$ alcohol dehydrogenase, $488.4 \mathrm{mg}$ nicotinamide, $10.6 \mathrm{mg}$ phenazine methosulfate, and $2.4 \mathrm{~mL}$ ethanol in $37.6 \mathrm{~mL}$ GlyGly buffer ( $65 \mathrm{mM}, \mathrm{pH} 7.4)$. After $10 \mathrm{~min}$, the A560nm was determined by a plate reader, and the readings were calibrated with $\mathrm{NAD}^{+}$standards. The protein concentrations were assessed by BCA Protein Assay (Thermo Scientific, Waltham,MA,USA).

\section{Flow cytometry-based Annexin V/7-AAD assay}

The apoptosis level of PC12 cells was determined by ApoScreen Annexin V kit (SouthernBiotech, Birmingham, AL, USA) according to the manufacturer's protocol. Briefly, cells were harvested by $0.25 \%$ trypsin solution, then washed by 
cold PBS. The cells were resuspended in $100 \mu$ cold $1 \mathrm{X}$ binding buffer $(10 \mathrm{mM}$ HEPES, pH 7.4, $140 \mathrm{mM} \mathrm{NaCl}, 2.5 \mathrm{mM} \mathrm{CaCl}_{2}, 0.1 \%$ BSA). Then $5 \mu \mathrm{L}$ of labeled Annexin V was added into the cell suspension. After incubation for $15 \mathrm{~min}$ on ice, the solution contained $200 \mu \mathrm{L} 1 \mathrm{X}$ binding buffer and $5 \mu \mathrm{L}$ 7-AAD was added into the cell suspensions. The number of stained cells was measured by a flow cytometer (FACSAria II, BD Biosciences).

\section{ATP assay}

Intracellular ATP levels were determined by an ATP Bioluminescence Assay Kit (Roche Applied Science, Mannheim, Germany), according to the manufacturer's protocols. Briefly, PC12 cells were washed once with PBS, lysed using the cell lysis reagent, and then the cell samples were mixed with $50 \mu$ of the luciferase reagent. The chemiluminescence of the samples was detected using a plate reader (Synergy2; Biotek, Winooski, Vermont, USA). The ATP levels were normalized to the protein concentrations of the samples, which were determined by BCA Protein Assay (Thermo Scientific, Waltham,MA,USA).

\section{Real-Time PCR assay}

After total RNA was extracted (TaKaRa MiniBEST Universal RNA Extraction Kit, Takara Bio, Dalian, China) from PC12 cells, 500 ng total RNA was reverse-transcribed to cDNA (Prime-Script RT reagent kit, Takara Bio, Dalian, China). The parameters set for reverse transcription were as follows: $37^{\circ} \mathrm{C}$ for 15 
min, then $85^{\circ} \mathrm{C}$ for $15 \mathrm{~s}$. Quantitative RT-PCR was performed by using SYBR Premix Ex Taq (Takara Bio, Dalian, China) and the following primers: Nampt (sense 5'- TATTCTGTTCCAGCGGCAGA $-3^{\prime}$ and anti-sense 5' GACCACAGACACAGGCACTGA -3') ; GAPDH (sense 5'CCTGCACCACCAACTGCTTA $-3^{\prime}$ and anti-sense 5'GGCCATCCACAGTCTTCTGA -3'). Assays were performed according to the following procedure: Denatured at $95^{\circ} \mathrm{C}$ for $10 \mathrm{~s}$, followed by 40 cycles of $95^{\circ} \mathrm{C}$ for $5 \mathrm{~s}$ and $60^{\circ} \mathrm{C}$ for $30 \mathrm{~s}$. The data were analyzed by using the comparative threshold cycle method, and the results were expressed as fold differences normalized to the mRNA level of GAPDH.

\section{Western blot assay}

After the various treatments, PC12 cells were washed once with PBS. Then the PC12 cells were harvested and lysed in RIPA buffer (Millipore, Temecula, California, USA) containing 1\% protease inhibitor cocktail (CWBio, Beijing, China) and $1 \mathrm{mM}$ phenylmethanesulfonyl fluoride. Lysates were centrifuged at 12,000 rpm for $10 \mathrm{~min}$ at $4^{\circ} \mathrm{C}$. After quantifications of the protein samples using BCA Protein Assay Kit (Pierce Biotechnology, Rockford, Illinois, USA), $30 \mu \mathrm{g}$ of total protein was electrophoresed through a 10\% sodium dodecyl sulfate-polyacrylamide gel and then transferred to $0.45-\mu \mathrm{m}$ nitrocellulose membranes. The blots were incubated overnight at $4^{\circ} \mathrm{C}$ with rabbit polyclonal Nampt antibody (1:2000 dilution, Abcam, Cambridge, UK) in TBST containing $1 \%$ bovine serum albumin (BSA) and then 
incubated with horse radish peroxidase-conjugated secondary antibody (1:3000 dilution, Epitomics, Hangzhou, Zhejiang Province, China) in TBST containing 1\% BSA at room temperature for $1 \mathrm{hr}$. A GAPDH antibody (proteintech, Wuhan, China) was used to normalize the sample. The intensities of the bands were quantified by densitometry using Gel-Pro Analyzer (Media Cybernetics, Silver Spring, Maryland, USA).

\section{Intracellular lactate dehydrogenase (LDH) assay}

Cell death was determined by measuring the intracellular lactate dehydrogenase (LDH) activity of the cells. In brief, cells were lysed for $20 \mathrm{~min}$ in lysing buffer containing $0.04 \%$ Triton X-100, $2 \mathrm{mM}$ HEPES and $0.01 \%$ bovine serum albumin ( $\mathrm{pH}$ 7.5). Then $50 \mu \mathrm{L}$ cell lysates were mixed with $150 \mu \mathrm{L}$ reaction buffer containing $0.34 \mathrm{mM} \mathrm{NADH}$ and $2.5 \mathrm{mM}$ sodium pyruvate (PH 7.5). The $\mathrm{A}_{340 \mathrm{~nm}}$ changes of the samples were monitored over $90 \mathrm{~s}$. Percentage of cell death was calculated by normalizing the LDH values of samples to the LDH values of the lysates of control.

\section{RNA interference}

When PC12 cells were approximately $40 \%$ confluent, the cells were transfected with Nampt siRNA sequences (sense 5'AGUAAGGAAGGUGAAAUACTT-3' and antisense ${ }^{\prime}$ GUAUUUCACCUUCCUUACUTT-3') and the scrambled control siRNA 
sequences. Lipofectamine 2000 (Invitrogen, Carlsbad, California, USA) was used for transfection according to the manufacturer's protocol. For each well of a 24-well plate, $100 \mu 1$ Opti-MEM containing $0.06 \mathrm{nmol}$ of the siRNA sequences and $2.5 \mu 1$ lipofectamine 2000 was added into $500 \mu \mathrm{l}$ culture media of the cells. After 6 hrs, the media was replaced by DMEM containing $10 \%$ fetal bovine serum.

\section{Statistical analyses}

All data are presented as mean \pm SEM. Data were assessed by one-way ANOVA, followed by Student - Newman - Keuls post hoc test, except where noted. $P$ values less than 0.05 were considered statistically significant.

\section{Results}

1.Nampt plays siginificant roles in both the $\mathrm{NAD}^{+}$synthesis and survival of PC12 cells under basal conditions

To investigate the roles of Nampt in the $\mathrm{NAD}^{+}$metabolism of PC12 cells under basal conditions, we determined the effects of the Nampt inhibitor FK866 on the intracellular NAD ${ }^{+}$levels of the cells. FK866 at the concentrations of 2, 5, 10, 20, and $50 \mathrm{nM}$ led to profound decreases in the intracellular $\mathrm{NAD}^{+}$levels (Fig. 1A), indicating a critical role of Nampt in the $\mathrm{NAD}^{+}$synthesis in the cells under basal conditions. We also applied FACS-based Annexin V/7-ADD assay to determine the roles of Nampt in the basal survival of the cells, showing that $10 \mathrm{nM}$ FK866 led to a significant increase in early-stage apoptosis, while both $20 \mathrm{nM}$ and $50 \mathrm{nM}$ FK866 led to significant 
increases in early-stage apoptosis (Annexin $\mathrm{V}^{+} / 7-\mathrm{ADD}^{-}$), late-stage apoptosis (Annexin $\mathrm{V}^{+} / 7-\mathrm{ADD}^{+}$) and necrosis (Annexin $\left.\mathrm{V}^{-} / 7-\mathrm{ADD}^{+}\right)($Figs. 1B and 1C). FK866 dosedependent increased cell death, which equlas to the sum of early-stage apoptosis (Annexin $\mathrm{V}^{+} / 7-\mathrm{ADD}^{-}$), late-stage apoptosis (Annexin $\mathrm{V}^{+} / 7-\mathrm{ADD}^{+}$) and necrosis (Annexin $\mathrm{V}^{-} / 7-\mathrm{ADD}^{+}$) (Figs. 1B and 1C).

We also applied Nampt siRNA to determine the effects of decreased Nampt on the survival of PC12 cells. Treatment of the cells with Nampt siRNA led to a significant decrease in the Nampt level (Supplemental Fig. 1A). The reduction of Nampt led to both a significant increase in the cell death (Supplemental Fig. 1B) and a significant decrease in the cell survival (Supplemental Fig. 1C).

\section{2. $\mathrm{H}_{2} \mathrm{O}_{2}$ produced significant decreases in both mRNA and protein levels of Nampt}

\section{in $\mathrm{PC12}$ cells}

We determined the effects of $\mathrm{H}_{2} \mathrm{O}_{2}$ on the Nampt mRNA levels of the PC12 cells at 12 or $20 \mathrm{hrs}$ after the $\mathrm{H}_{2} \mathrm{O}_{2}$ treatment. Treatment of the cells with 0.1 or $0.3 \mathrm{mM} \mathrm{H}_{2} \mathrm{O}_{2}$ led to significant increases in the Nampt mRNA level of the cells at $12 \mathrm{hrs}$ after the $\mathrm{H}_{2} \mathrm{O}_{2}$ treatment (Fig. 2A). In contrast, $\mathrm{H}_{2} \mathrm{O}_{2}$ led to significant decreases in the Nampt mRNA level at $20 \mathrm{hrs}$ after the $\mathrm{H}_{2} \mathrm{O}_{2}$ treatment (Fig. 2A).

We also determined the effects of $\mathrm{H}_{2} \mathrm{O}_{2}$ on the Nampt protein levels of the cells at 12,24 or 48 hrs after the $\mathrm{H}_{2} \mathrm{O}_{2}$ treatment. $\mathrm{H}_{2} \mathrm{O}_{2}$ did not significantly affect the level of Nampt at 12 hrs after the $\mathrm{H}_{2} \mathrm{O}_{2}$ treatment (Figs. 2B and 2E). In contrast, $\mathrm{H}_{2} \mathrm{O}_{2}$ led to significant decreases in the Nampt protein level at both 24 (Figs. 2C and 2E) and $48 \mathrm{hrs}$ 
(Figs. 2D and 2E) after the $\mathrm{H}_{2} \mathrm{O}_{2}$ treatment.

\section{3. $\mathrm{H}_{2} \mathrm{O}_{2}$-produced decrease in the Nampt levels plays a significant role in $\mathrm{H}_{2} \mathrm{O}_{2}$ - produced cell death}

To investigate the biological consequences of the $\mathrm{H}_{2} \mathrm{O}_{2}$-produced decrease in the Nampt levels of PC12 cells, we applied FACS-based Annexin V/7-ADD assay to determine the effects of the Nampt inhibitor FK866 on $\mathrm{H}_{2} \mathrm{O}_{2}$-produced cell death. FK866 significantly exacerbated $\mathrm{H}_{2} \mathrm{O}_{2}$-produced early-stage apoptosis (Annexin $\mathrm{V}^{+} / 7$ $\left.\mathrm{ADD}^{-}\right)$, late-stage apoptosis $\left(\right.$Annexin $\left.\mathrm{V}^{+} / 7-\mathrm{ADD}^{+}\right)$and necrosis $\left(\right.$Annexin $\left.\mathrm{V}^{-} / 7-\mathrm{ADD}^{+}\right)$

(Figs. 3A and 3B). Nampt siRNA treatment also significantly exacerbated the $\mathrm{H}_{2} \mathrm{O}_{2}-$ produced cell death, asssesed by LDH assay (Supplemental Fig. 1D). To further investigate the biological consequences of the $\mathrm{H}_{2} \mathrm{O}_{2}$-produced decreases in the Nampt protein levels of PC12 cells, we determined the effects of the Nampt activator P7C3 on the $\mathrm{H}_{2} \mathrm{O}_{2}$-produced cell death. P7C3 significantly attenuated $\mathrm{H}_{2} \mathrm{O}_{2}$-produced decrease in the cell survival (Fig. 3C). Our study also showed that $\mathrm{FK} 866$ and $\mathrm{H}_{2} \mathrm{O}_{2}$ produced synergistic effects to decrease the intracellular ATP levels (Fig. 4).

\section{Discussion}

The major findings of our current study include: First, Nampt plays significant roles in both the $\mathrm{NAD}^{+}$synthesis and survival of the cells under basal conditions; second, $\mathrm{H}_{2} \mathrm{O}_{2}$ produced significant decreases in both the mRNA and the protein levels of Nampt; and third, $\mathrm{H}_{2} \mathrm{O}_{2}$ induced cell death partially by producing the decreases in 
the mRNA and protein levels of Nampt, since the Nampt inhibitor or the Nampt activator significantly exacerbated or attenuated the $\mathrm{H}_{2} \mathrm{O}_{2}$-induced cell death, respectively.

Cumulating evidence has indicated critical roles of impaired $\mathrm{NAD}^{+}$metabolism in both aging and a number of major diseases (1, 2, 3 ), indicating critical significance to investigate the mechanisms underlying $\mathrm{NAD}^{+}$deficiency under these conditions $(1$, 2, 3 ). Under in the tissues or organs certain pathological conditions, including the metabolic organs that are exposed to HFD (16), Drosophila pink1 mutants (17), and aging $(16,18)$, decreased levels of Nampt have been reported. However, there is significant deficiency in the mechanisms underlying the Nampt alterations under pathological conditions.

Our current study has indicated that $\mathrm{H}_{2} \mathrm{O}_{2}$ was capable of decreasing both the mRNA and protein levels of Nampt in PC12 cells. Since there is significantly increased oxidative stress in aging and the pathological conditions (20-22), our finding has suggested a novel mechanism underlying the decreased Nampt in aging and multiple pathological conditions. Due to the critical roles of $\mathrm{NAD}^{+}$deficiency in aging and multiple major diseases, our study has suggested a significant mechanism underlying the pathological alterations of in aging and the diseases: The oxidative stress in the diseases and aging can lead to decreased Nampt, leading to decreased $\mathrm{NAD}^{+}$synthesis thus resulting multiple pathological changes.

Our study has also indicated that Nampt plays a significant role in oxidative stress-induced cell death, since the Nampt inhibitor or the Nampt activator significantly 
exacerbated or attenuated the $\mathrm{H}_{2} \mathrm{O}_{2}$-induced cell death, respectively. These observations have suggested a novel mechanism underlying oxidative stress-induced cell death at least for some cell types.

There are two $\mathrm{NAD}^{+}$synthesis pathways in cells, while the roles of Nampt in the both general $\mathrm{NAD}^{+}$-generating capacity and survival of various cell types under basal conditions are largely unclear. Our current study has indicated that Nampt plays critical roles in both the $\mathrm{NAD}^{+}$synthesis and cell survival of differentiated PC12 cells under basal conditions, since the Nampt inhibitor FK866 produced profound decreases in both the intracellular $\mathrm{NAD}^{+}$levels and survival of the cells under basal conditions.

Collectively, our study has indicated significant roles of Nampt in the survival of PC12 cells under both basal and oxidative stress conditions. Our study has also indicated a novel mechanism underlying the decreases in Nampt in multiple pathological conditions and aging. Moreover, our study has suggested a novel mechanism underlying oxidative cell death. 


\section{Acknowledgment:}

The authors would like to acknowledge the financial support by two research grants from a Major Special Program Grant of Shanghai Municipality (Grant \# 2017SHZDZX01) (to W.Y.) and a Major Research Grant from the Scientific Committee of Shanghai Municipality \#16JC1400502 (to W.Y.). 


\section{References:}

1. Ying, W. (2008) $\mathrm{NAD}^{+} / \mathrm{NADH}$ and $\mathrm{NADP}^{+} / \mathrm{NADPH}$ in cellular functions and cell death: regulation and biological consequences. Antioxid Redox Signal 10, $179-206$

2. Ying, W. (2006) $\mathrm{NAD}^{+}$and NADH in cellular functions and cell death. Front Biosci 11, 3129-3148

3. Zhang, M. C., and Ying, W. H. (2019) NAD ${ }^{+}$Deficiency Is a Common Central Pathological Factor of a Number of Diseases and Aging: Mechanisms and Therapeutic Implications. Antioxidants \& Redox Signaling 30, 890-905

4. Ying, W., Wei, G., Wang, D., Wang, Q., Tang, X., Shi, J., Zhang, P., and Lu, H. (2007) Intranasal administration with $\mathrm{NAD}^{+}$profoundly decreases brain injury in a rat model of transient focal ischemia. Front Biosci 12, 2728-2734

5. Zheng, C., Han, J., Xia, W., Shi, S., Liu, J., and Ying, W. (2012) NAD ${ }^{+}$ administration decreases ischemic brain damage partially by blocking autophagy in a mouse model of brain ischemia. Neurosci Lett 512, 67-71

6. Zhang, Y., Wang, B., Fu, X., Guan, S., Han, W., Zhang, J., Gan, Q., Fang, W., Ying, W., and Qu, X. (2016) Exogenous NAD ${ }^{+}$administration significantly protects against myocardial ischemia/reperfusion injury in rat model. $A m \mathrm{~J}$ Transl Res 8, 3342-3350

7. Won, S. J., Choi, B. Y., Yoo, B. H., Sohn, M., Ying, W., Swanson, R., and Suh, S. W. (2012) Prevention of traumatic brain injury-induced neuron death by intranasal delivery of $\mathrm{NAD}^{+} . J$ Neurotrauma 29, $1401-9$ 
8. Liu, J., Yang, B., Zhou, P., Kong, Y., Hu, W., Zhu, G., Ying, W., Li, W., Wang, Y., and Li, S. (2017) Nicotinamide adenine dinucleotide suppresses epileptogenesis at an early stage. Sci Rep 7, 7321

9. Sheng, C., Chen, H., Wang, B., Liu, T., Hong, Y., Shao, J., He, X., Ma, Y., Nie, H., Liu, N., Xia, W., and Ying, W. (2012) NAD ${ }^{+}$administration significantly attenuates synchrotron radiation X-ray-induced DNA damage and structural alterations of rodent testes. Int J Physiol Pathophysiol Pharmacol 4, 1-9

10. Wang, B., Ma, Y., Kong, X., Ding, X., Gu, H., Chu, T., and Ying, W. (2014) $\mathrm{NAD}^{+}$administration decreases doxorubicin-induced liver damage of mice by enhancing antioxidation capacity and decreasing DNA damage. Chem Biol Interact 212, 65-71

11. Mills, K. F., Yoshida, S., Stein, L. R., Grozio, A., Kubota, S., Sasaki, Y., Redpath, P., Migaud, M. E., Apte, R. S., Uchida, K., Yoshino, J., and Imai, S. I. (2016) Long-Term Administration of Nicotinamide Mononucleotide Mitigates AgeAssociated Physiological Decline in Mice. Cell Metab 24, 795-806

12. Frederick, D. W., Loro, E., Liu, L., Davila, A., Jr., Chellappa, K., Silverman, I. M., Quinn, W. J., 3rd, Gosai, S. J., Tichy, E. D., Davis, J. G., Mourkioti, F., Gregory, B. D., Dellinger, R. W., Redpath, P., Migaud, M. E., Nakamaru-Ogiso, E., Rabinowitz, J. D., Khurana, T. S., and Baur, J. A. (2016) Loss of NAD Homeostasis Leads to Progressive and Reversible Degeneration of Skeletal Muscle. Cell Metab 24, 269-282 
13. Son, M. J., Kwon, Y., Son, T., and Cho, Y. S. (2016) Restoration of Mitochondrial $\mathrm{NAD}^{+}$Levels Delays Stem Cell Senescence and Facilitates Reprogramming of Aged Somatic Cells. Stem Cells 34, 2840-2851

14. Magni, G., Amici, A., Emanuelli, M., Orsomando, G., Raffaelli, N., and Ruggieri, S. (2004) Enzymology of $\mathrm{NAD}^{+}$homeostasis in man. Cell Mol Life Sci 61, 19-34

15. Revollo, J. R., Grimm, A. A., and Imai, S. (2007) The regulation of nicotinamide adenine dinucleotide biosynthesis by Nampt/PBEF/visfatin in mammals. Curr Opin Gastroenterol 23, 164-170

16. Yoshino, J., Mills, K. F., Yoon, M. J., and Imai, S. (2011) Nicotinamide mononucleotide, a key $\mathrm{NAD}^{+}$intermediate, treats the pathophysiology of dietand age-induced diabetes in mice. Cell Metab 14, 528-536

17. Lehmann, S., Loh, S. H., and Martins, L. M. (2017) Enhancing NAD ${ }^{+}$salvage metabolism is neuroprotective in a PINK1 model of Parkinson's disease. Biol Open 6, 141-147

18. Jokinen, R., Pirnes-Karhu, S., Pietilainen, K. H., and Pirinen, E. (2017) Adipose tissue $\mathrm{NAD}^{+}$-homeostasis, sirtuins and poly(ADP-ribose) polymerases important players in mitochondrial metabolism and metabolic health. Redox Biol 12, 246-263

19. Alano, C. C., Ying, W., and Swanson, R. A. (2004) Poly(ADP-ribose) polymerase-1-mediated cell death in astrocytes requires $\mathrm{NAD}^{+}$depletion and mitochondrial permeability transition. J Biol Chem 279, 18895-18902 
20. Ureshino, R. P., Rocha, K. K., Lopes, G. S., Bincoletto, C., and Smaili, S. S. (2014) Calcium signaling alterations, oxidative stress, and autophagy in aging. Antioxid Redox Signal 21, 123-137

21. Zuo, L., Prather, E. R., Stetskiv, M., Garrison, D. E., Meade, J. R., Peace, T. I., and Zhou, T. (2019) Inflammaging and Oxidative Stress in Human Diseases: From Molecular Mechanisms to Novel Treatments. Int J Mol Sci 20, 4472

22. Rani, V., Deep, G., Singh, R. K., Palle, K., and Yadav, U. C. (2016) Oxidative stress and metabolic disorders: Pathogenesis and therapeutic strategies. Life Sci 148, 183-193 


\section{Figure Legends:}

Fig. 1. Nampt plays a siginificant role in the $\mathrm{NAD}^{+}$synthesis and basal survival of differentiated PC12 cells. (A) FK866 at the concentrations of 2, 5, 10, 20, and 50 $\mathrm{nM}$ led to profound decreases in the intracellular $\mathrm{NAD}^{+}$levels. $\mathrm{NAD}^{+}$assays were conducted $12 \mathrm{hrs}$ after the cells were treated with 2, 5, 10, 20, and $50 \mathrm{nM} \mathrm{FK866.} N=$ 8. The data were pooled from three independent experiments. ***, $P<0.001$. (B,C) 10 nM FK866 led to a significant increase in early-stage apoptosis, while both $20 \mathrm{nM}$ and $50 \mathrm{nM}$ FK866 led to significant increases in early-stage apoptosis (Annexin $\mathrm{V}^{+} / 7$ $\left.\mathrm{ADD}^{-}\right)$, late-stage apoptosis $\left(\right.$Annexin $\mathrm{V}^{+} / 7-\mathrm{ADD}^{+}$) and necrosis $\left(\right.$Annexin $\mathrm{V}^{-} / 7-\mathrm{ADD}^{+}$). PC12 cells were treated with 2, 5, 10, 20, and $50 \mathrm{nM} \mathrm{FK} 866$ for 24 hrs. $N=6$. The data were pooled from three independent experiments. **, $P<0.01 ; * * *, P<0.001$.

Fig. 2. $\mathrm{H}_{2} \mathrm{O}_{2}$ produced significant decreases in both Nampt mRNA levels and Nampt protein levels of PC12 cells. (A) Treatment of PC12 cells with $0.1 \mathrm{mM}$ or $0.3 \mathrm{mM} \mathrm{H}_{2} \mathrm{O}_{2}$ led to significant increases in the Nampt mRNA level of the cells at 12 hrs after the $\mathrm{H}_{2} \mathrm{O}_{2}$ treatment. In contrast, $\mathrm{H}_{2} \mathrm{O}_{2}$ led to significant decreases in the Nampt mRNA level of the cells at $20 \mathrm{hrs}$ after the $\mathrm{H}_{2} \mathrm{O}_{2}$ treatment. PC12 cells were treated with $0.1,0.3 \mathrm{mM} \mathrm{H}_{2} \mathrm{O}_{2}$ for 12 or $20 \mathrm{hrs} . N=6$. The data were pooled from three independent experiments. *, $P<0.05$; **, $P<0.01$. (B) Effects of $\mathrm{H}_{2} \mathrm{O}_{2}$ on the protein level of Nampt at 12 hrs after the $\mathrm{H}_{2} \mathrm{O}_{2}$ treatment. (C) Effects of $\mathrm{H}_{2} \mathrm{O}_{2}$ on the protein level of Nampt at $24 \mathrm{hrs}$ after the $\mathrm{H}_{2} \mathrm{O}_{2}$ treatment. (D) Effects of $\mathrm{H}_{2} \mathrm{O}_{2}$ on the protein level of Nampt at 48 hrs after the $\mathrm{H}_{2} \mathrm{O}_{2}$ treatment. (E) $\mathrm{H}_{2} \mathrm{O}_{2}$ did not significantly affect the level 
of Nampt at $12 \mathrm{hrs}$ after the $\mathrm{H}_{2} \mathrm{O}_{2}$ treatment. In contrast, $\mathrm{H}_{2} \mathrm{O}_{2}$ led to significant decreases in the Nampt protein level of the cells at both 24 and $48 \mathrm{hrs}$ after the $\mathrm{H}_{2} \mathrm{O}_{2}$ treatment. PC12 cells were treated with $0.1,0.3 \mathrm{mM} \mathrm{H}_{2} \mathrm{O}_{2}$ for 12,24 , or $48 \mathrm{hrs} . N=9$. The data were pooled from three independent experiments. $*, P<0.05 ; * *, P<0.01$.

\section{Fig. 3. Nampt inhibitor FK866 and Nampt activator P7C3 significantly} exacerbated or attenuated $\mathrm{H}_{2} \mathrm{O}_{2}$-produced cell death of differentiated PC12 cells, respectively. (A, B) FK866 significantly exacerbated $\mathrm{H}_{2} \mathrm{O}_{2}$-produced early-stage apoptosis (Annexin $\mathrm{V}^{+} / 7-\mathrm{ADD}^{-}$), late-stage apoptosis (Annexin $\mathrm{V}^{+} / 7-\mathrm{ADD}^{+}$) and necrosis $\left(\right.$ Annexin $\left.\mathrm{V}^{-} / 7-\mathrm{ADD}^{+}\right)$of the cells. PC12 cells were pre-treated with $10 \mathrm{nM}$ FK866 for $30 \mathrm{~min}$, and then co-treated with $0.3 \mathrm{mM} \mathrm{H}_{2} \mathrm{O}_{2}$ for $23.5 \mathrm{hrs} . N=6$. The data were pooled from three independent experiments. *, $P<0.05 ; * *, P<0.01 ; * * *, P<$ 0.001. (C) Nampt activator P7C3 significantly attenuated $\mathrm{H}_{2} \mathrm{O}_{2}$-produced decrease in the cell survival. PC12 cells were pre-treated with $10 \mu \mathrm{M}$ P7C 3 for 4 hrs, and then cotreated with $0.3 \mathrm{mM} \mathrm{H}_{2} \mathrm{O}_{2}$ for $20 \mathrm{hrs} . N=9$. The data were pooled from three independent experiments. $* * *, P<0.001$.

Fig. 4. Nampt inhibitor FK866 significantly exacerbated $\mathrm{H}_{2} \mathrm{O}_{2}$-produced decreases in the intracellular ATP levels of PC12 cells. FK866 and $\mathrm{H}_{2} \mathrm{O}_{2}$ produced synergistic effects to decrease the intracellular ATP levels. PC12 cells were pre-treated with $10 \mathrm{nM}$ FK866 for $30 \mathrm{~min}$, and then co-treated with $0.3 \mathrm{mM} \mathrm{H}_{2} \mathrm{O}_{2}$ for $1 \mathrm{hr} . N=6$. The data were pooled from three independent experiments. $* * *, P<0.001$. 


\section{Legends of Supplemental Figures}

\section{Supplemental Figure 1. Nampt siRNA-produced reduction of Nampt led to a} significant increase in differentiated PC 12 cell death. (A) Treatment of the cells with Nampt siRNA led to a significant decrease in the Nampt level. PC12 cells were transfected with control or Nampt siRNA sequences for $48 \mathrm{hrs} . N=12$. The data were pooled from three independent experiments. ***, $P<0.001$. (B, C) The reduction of Nampt led to a significant increase in the cell death. PC12 cells were transfected with control or Nampt siRNA sequences for $48 \mathrm{hrs} . N=9$. The data were pooled from three independent experiments. $*, P<0.05$; $* * *, P<0.001$. (D) The reduction of Nampt exacerbated $\mathrm{H}_{2} \mathrm{O}_{2}$-produced cell death. PC12 cells were transfected with control or Nampt siRNA sequences for $24 \mathrm{hrs}$, and then incubated by $0.3 \mathrm{mM} \mathrm{H}_{2} \mathrm{O}_{2}$ for $24 \mathrm{hrs.} N$ $=9$. The data were pooled from three independent experiments. $* * *, P<0.001$. 
A

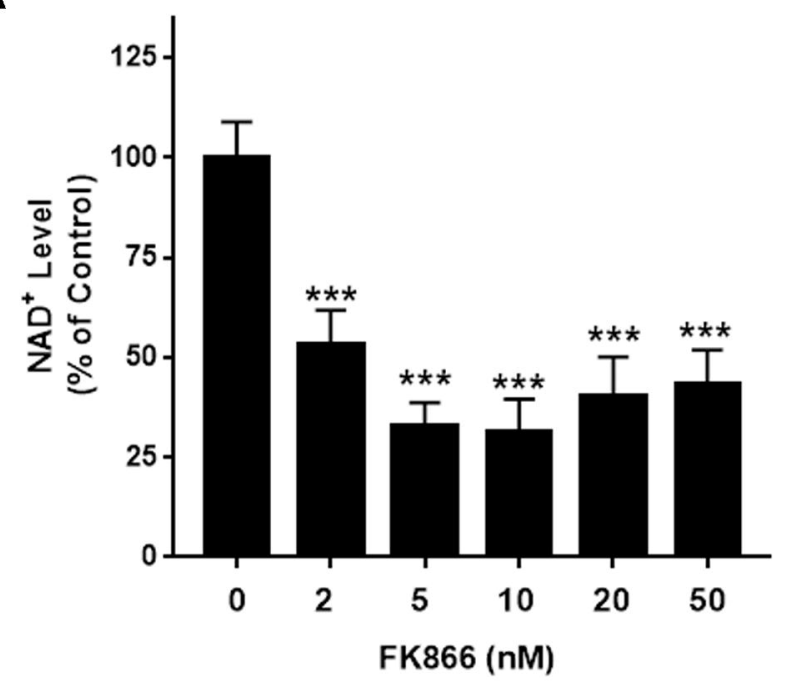

B

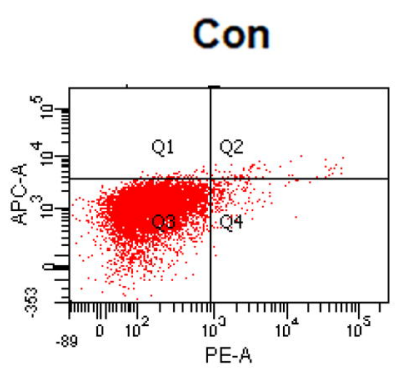

20 nM FK866

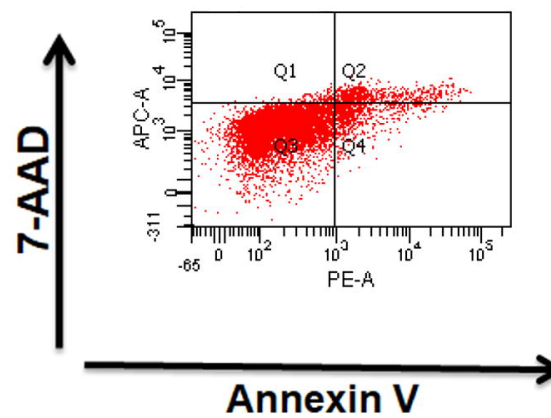

10 nM FK866

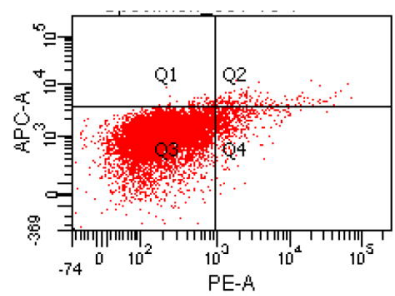

50 nM FK866

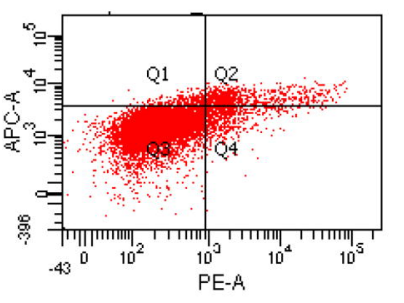

C

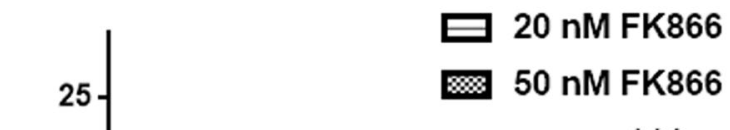

Control

ه 10 nM FK866

K866

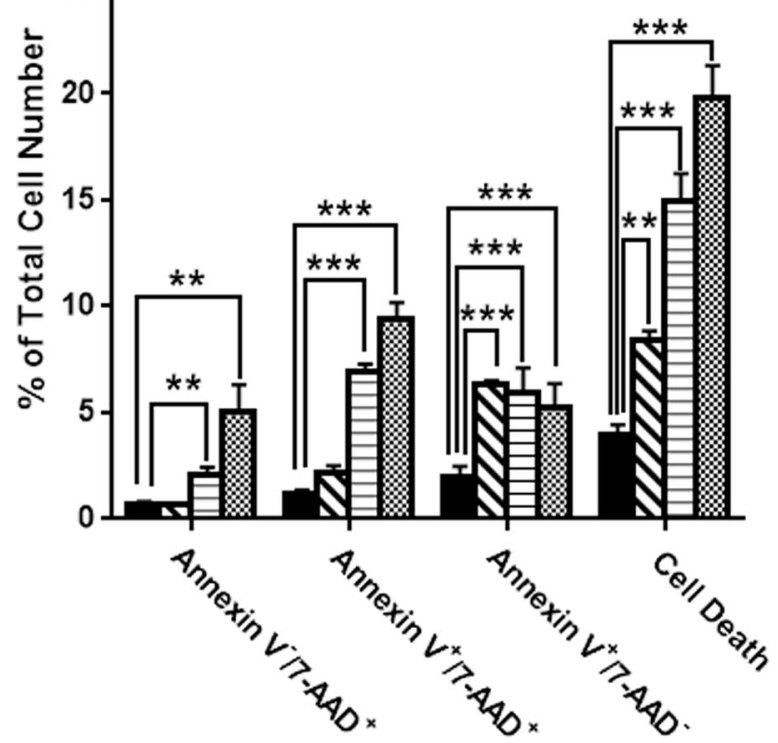




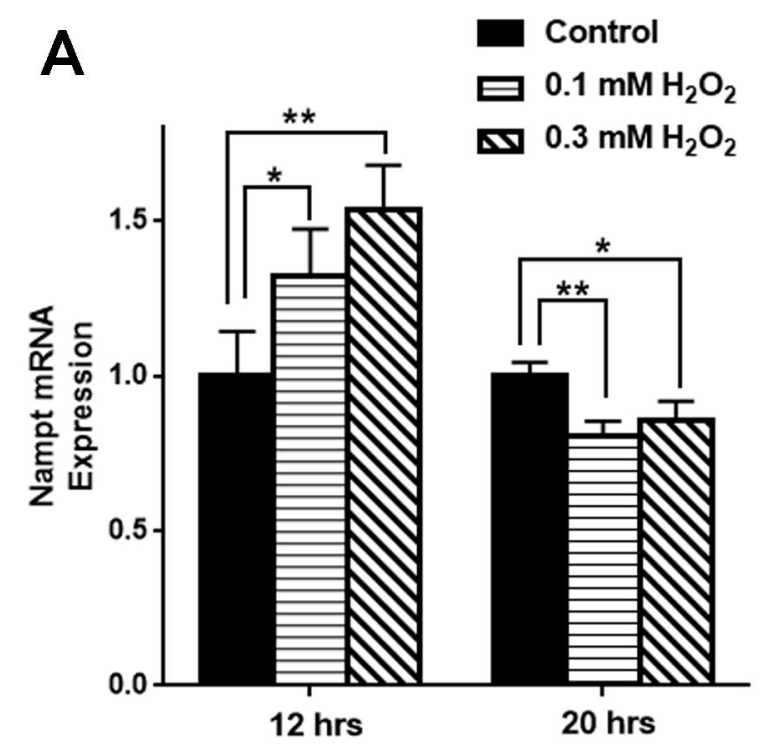

B

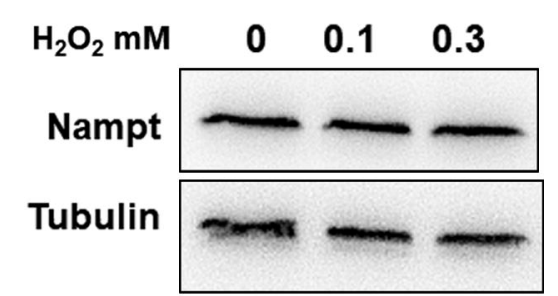

$\begin{array}{lllll}C & \mathrm{H}_{2} \mathrm{O}_{2} \mathrm{mM} & 0 & 0.1 & 0.3\end{array}$

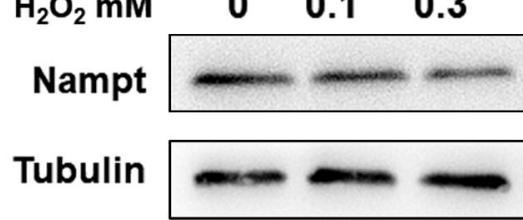

$\begin{array}{lllll}D & \mathrm{H}_{2} \mathrm{O}_{2} \mathrm{mM} & 0 & 0.1 & 0.3\end{array}$

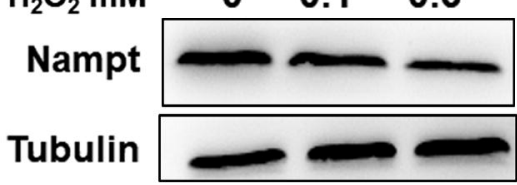

12 hrs

E

- Control

曰 $0.1 \mathrm{mM} \mathrm{H}_{2} \mathrm{O}_{2}$ ه $0.3 \mathrm{mM} \mathrm{H}_{2} \mathrm{O}_{2}$

24 hrs

48 hrs

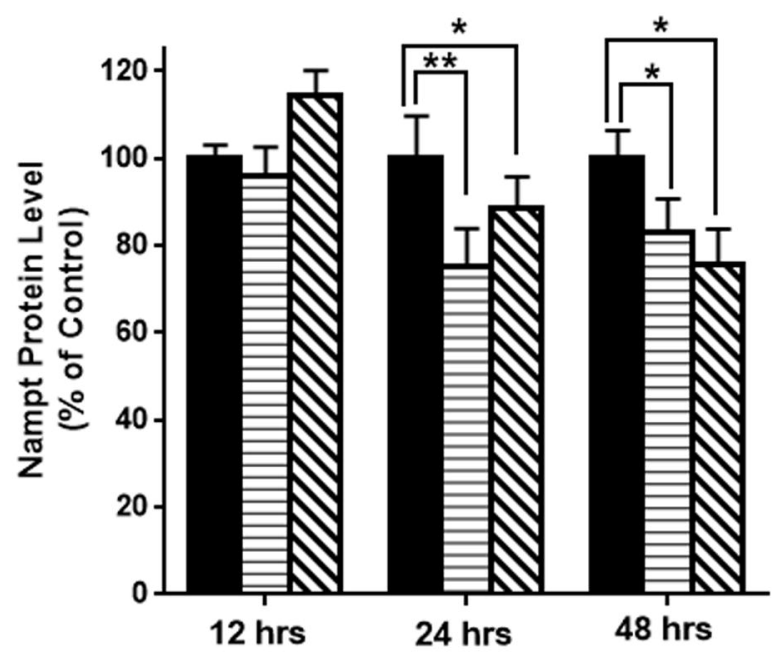



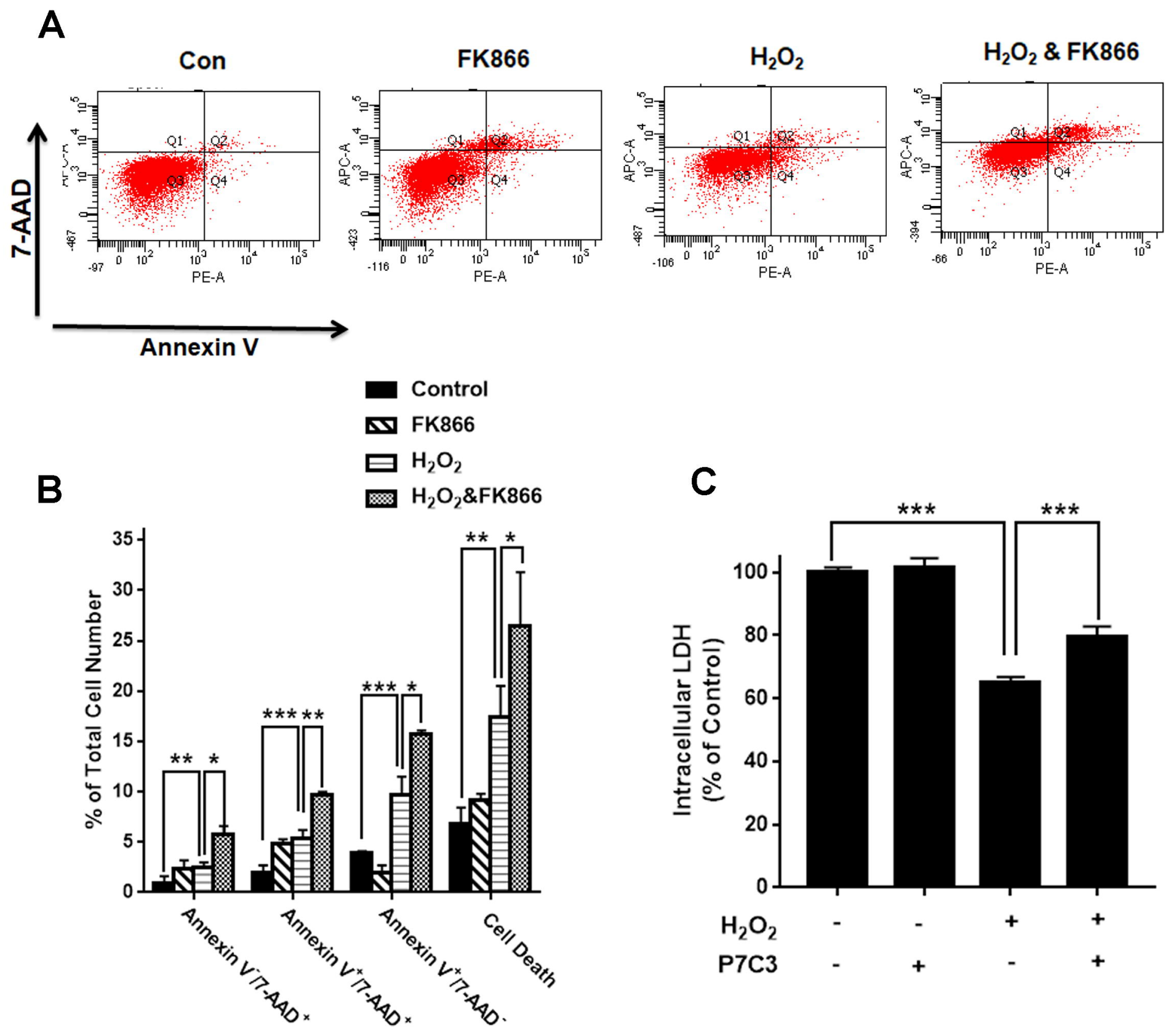


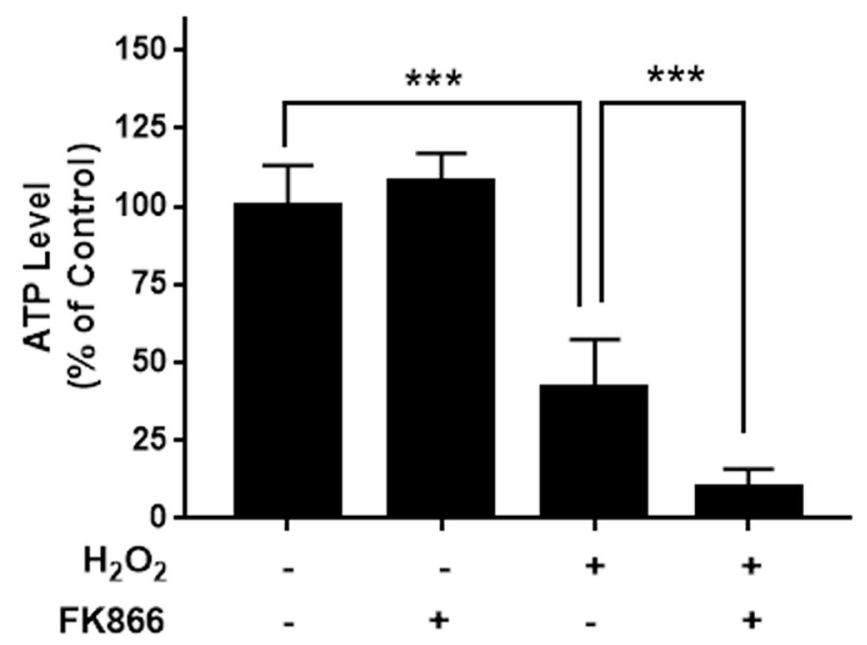

